\title{
On the Prescription Translation of Traditional Chinese Medicine
}

\author{
Le Xiong* \\ Xi'an Eurasia University, Xi'an, Shaanxi, 710065, China
}

\begin{tabular}{|c|c|}
\hline ARTICLE INFO & ABSTRACT \\
\hline Article history & Traditional Chinese Medicine (TCM) is an essential legacy of Chinese \\
\hline Received: 17 July 2021 & culture, which makes a great contribution to China and the world's medical \\
\hline Revised: 25 July 2021 & fields. To make it accepted by more people from different countries, the \\
\hline Accepted: 15 October 2021 & translation of TCM becomes important. As an important branch of TCM, \\
\hline Published Online. 30 Octoher 2021 & $\begin{array}{l}\text { the study of prescription promotes the development of TCM, and its } \\
\text { translation is also significant. However, there are various problems in TCM }\end{array}$ \\
\hline 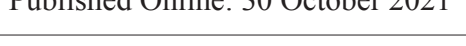 & prescription translation and there are few standards in TCM translation. \\
\hline Keywords: & Thus, this research uses Christiane Nord's "Functionality plus Loyalty" \\
\hline Prescription translation & $\begin{array}{l}\text { Translation Theory to analyze the TCM prescription translation. Based } \\
\text { on characteristics of prescription formation, the paper applies Christiane }\end{array}$ \\
\hline Christiane Nord & Nord's "Functionality plus Loyalty" theory to TCM prescription translation. \\
\hline Functionality plus Loyalty & $\begin{array}{l}\text { It draws a conclusion that TCM prescription translation can be done } \\
\text { according to "Functionality plus Loyalty" theory, and there are three } \\
\text { ways of prescription names translation. They are literal translation, free } \\
\text { translation and transliteration. }\end{array}$ \\
\hline
\end{tabular}

\section{Introduction}

It is known that traditional Chinese medicine translation is an important science which has promoted the medical development around the world. The prescription is a small branch of traditional Chinese medicine (TCM). For the further study and spread of prescription of TCM, prescription translation of TCM becomes vital and significant. However, there are still a lot of problems in its translation. It is essential and significant to find some appropriate translation principles and methods of TCM prescription.

\section{TCM Prescriptions and Features}

The TCM prescription names' translation is a field worth studying to make it easily understood in the process of exchange and research ${ }^{[1]}$. However, there are still a lot

of problems in its translation, including poor readability, ambiguity, and complexity ${ }^{[2]}$.

The prescription names' translation is complicated, because its formative methods have nearly eleven ways. Jun, Chen, Zuo and Shi are basic elements of prescription. Jun is the principal component and plays the main role in prescription's effect. It is for the main symptoms and illness. Chen certainly assists Jun to augment principal medical component's effect. Besides, it is mainly for accompanied symptom. Zuo is complement in prescription. It helps Jun and Chen to make the herbs more effective called due complements; it is for minor accompanied symptoms; even it helps weaken the toxicity and violence called diminution complement. Sometimes it is used for contrary complement. Shi is a kind of mediation guide and harmonizing guide used as a mediator. It is not difficult to see that Jun, Chen, Zuo and

*Corresponding Author:

Le Xiong,

Xi'an Eurasia University, Xi'an, Shaanxi, 710065, China;

Email:xiongle@eurasia.edu 
Shi are different in their perspective role and effect. Their names are profoundly influenced by Chinese culture in monarchy areas.

There are mainly seventeen forms of prescription: decoction, powder, pill (bolus and pellet), paste, wine, sublimed preparation, medical tea, distillate formula, lozenge, stripe formula (medical cone), thread formula, suppository formula, granule, tablet, syrup, oral liquid, and injection. Decoction is a kind of liquid by dipping the medicine in water or wine, then decoct and get rid of dregs. Decoction is mainly internal medicine, such as " 麻 黄汤 ", " 小承气汤 ". The external medicine of decoction is for bath, fumigation, and gargle. Powder is to pulverize different medicines and mix together. It also divides internal and external medicine, for example, " 七厘散 ", " 银尧散", "金黄散", "生肌散", "八宝眼药", "冰嗍散"。 Pill is solid through combining the fine powder or medical extractive with binder, for example, " 六味地黄丸 ", " 安宫牛黄丸", " 舟车丸". It consists of honeyed pill, watered pill, flour and water paste pill, and concentrated pellet. Paste is made by boiling medicine in water and oil, then getting rid of residue. It is comprised of electuary, ointment and plaster, for example, " 鹿胎膏 ", " 八珍益母 膏 ", " 狗皮膏 ", " 暖脐膏 ". Wine is also called medical liquor. The medicine is bathed in white wine or rice wine, getting rid of dregs, for example, " 风湿药酒 ", " 参茸药 酒 ", "五加皮酒 ". Sublimed preparation has no certain form. Its value and effectiveness decides its name, for example, " 至宝丹 ", " 活络丹 ". Medical tea is rough powder or block-shaped powder and it is taken as tea, for example, " 午时茶 ", " 刺五加茶 ", " 减肥茶 ". Distillate formula is using fresh evaporable medical component to make a kind of fragrant water solution, for example, " 金 银花露 ", " 青蒿露 ". Lozenge is a kind of fine powder or solid, for example, " 紫金锭 ", " 万应锭 ". Stripe formula uses mulberry paper with medicine to twist into strips, for example, " 红升丹药条剂 ". Thread formula is making silk thread and cotton thread boil in medical liquid and used as external medicine as it dries. Suppository formula is mixing the fine powder and matrix to make a solid medicine, for example, " 小儿解热检 ", " 消痣检 ". Granule is a kind of dry powder or block shaped medicine, for example, " 感冒退热冲剂 ", "复方羚角冲剂 ". Tablet is formed by fine powder or medical extractive and some accessory, like " 口含片 ", " 泡腾片 ". Syrup is a kind of concentrated sugar water, for example, " 止咳糖浆 ", " 桂 皮糖浆". Oral liquid is made by extractive from medicine by water or other solvents, like " 人参蜂王浆口服液", " 枸杞地黄口服液 ". Injection is a kind of aseptic liquor and aseptic powder, for example, " 清开灵注射液 ", " 生 脉注射液 ".
Different prescription names adhere to different formation methods. There are eleven methods of prescription names' formation. First, the prescription names after its comprised herbs' names, like " 麻杏石甘 汤 ". Second, prescription names are from their principal herbs, such as "桂枝汤 ". Third, the prescription names after its number of herbs' types for it is composed of different kinds of herbs, like " 四物汤 ". Forth, prescription names consist of the herbs' number and processing methods, for example," 十灰散 ", " 四生丸 ". Fifth, naming after the guide herbs, like "十麥汤". Sixth, naming in a metaphor way, such as "舟车丸". Seventh, naming after their effects, for example, " 温脾汤 ". Eight, naming after principal herbs and prescription effect, like "黄连解毒 丸 ". Ninth, using principal herbs and the number of the rests' herbs, such as " 当归六黄丸 ". Tenth, naming after color, like " 桃花汤 ". Eleventh, some prescription names originate from Yi Gua, for example, " 交泰丸 ", " 清宁 丸 ". All of these rules are normal, and certainly there are some unusual methods. In this research, the main aim is analyzing usual and regular prescription names' translation.

\section{Christiane Nord's "Functionality plus Loyalty" Translation Theory}

It is known that Christiane Nord's "Functionality plus Loyalty", based on German functionalist methodology in 1970s, is still popular and practical. The "Functionality plus Loyalty " refers to the translator should aim at producing functional target text which conforms to the requirement of the translation skopos fixed by the initiator, respecting, at the same time, the legitimate interests of both the author of the origin and the readers of the translation ${ }^{[3]}$.

To apply "Functionality plus Loyalty" to source texts in the translation process, translators should be clear about the requirement from the client before translating, which is called "brief ${ }^{[4] "}$. An ideal brief includes the expected function of target texts, readers, media, publishing time and place, etc. Then translators should analyze the source texts, which is instructive to translation process. Through analyzing the source texts, translators would understand whether the source text is translatable, how much information of source text is related to the function of target text, what kind of translation strategy should be used to be in line with brief made before translation. This kind of analysis is helpful for translators to decide what kind of information should be remained and what kind should be deleted, and to choose or adjust appropriate translation strategies in accordance to function of target text.

DOI: http://dx.doi.org/10.26549/jetm.v5i2.7301 
In her Translating as a Purposeful Activity Functionalist Approaches Explained, she demonstrated that function was essential for any source text $\mathrm{t}^{[5]}$. Like the skopos theory not only adapted to different strategies according to different translation situations, but also coincided with the change of paradigm in some disciplines. It was pragmatic, because it could meet the needs and expectation of receivers of the target text in a communicative intention. Translation of prescription is for medical or cultural exchanges and communication. Therefore, the aim is clear and in line with the purpose of functional approach.

Functionality is important, the loyalty is appropriate as well. It is a methodology of culture-oriented, focusing on the differences between different cultures. Functionalist theory is practical because it paid heed to the target text's function. While, in Translating as a Purposeful Activity Functionalist Approaches Explained, she held that Skopos rules could be easily interpreted as "the ends justify the means ${ }^{[5] "}$. Readers certainly wanted the target text to be faithful to the source text, and she thought that certain ranges should be added to skopos theory. That is loyalty, not fidelity. "Loyalty means that the targettext purpose should be compatible with the original author's intentions ${ }^{[5] "}$. Loyalty demanded translators to consider the difference between culture-specific concepts and respect the authors' individual communicative intentions. As for the TCM prescription, a part of Chinese traditional culture, demands a method that can break down the cultural obstacles, respect both the Chinese and foreigners. In this way, Christiane Nord's "Functionality plus Loyalty" seems appropriate.

\section{Prescription Names' Translation Methods}

\subsection{Literal Translation of Prescription Names}

Literal translation means translating original text in an honest way that is word by word. It emphasizes the honesty and order of translation.

As is mentioned above, there are eleven ways of prescription names' formation, and translate prescription names through literal translation in nine conditions. First, if they are naming after their comprised herb's name, like " 葛根汤 " can be translated into "Decoction of Pueraria Root"; Second, if they are naming after their principal herbs, like " 桂枝汤" can be translated into "Cinnamon Twig Decoction" or "Decoction of Cinnamon Twig ". Third, if they are naming after the number of herbs' types, like " 四物汤 " can be translated into "Decoction of Four Drugs "or" Decoction of Four Ingredients". Fourth, if they are formed of herbs' number and process methods, like " 四生丸 " can be translated into "Bolus of Four Fresh
Drugs". Fifth, if they are composed of guide herbs, like " 十丰汤 " can be translated into "Decoction of (with) Ten Chinese Dates" "Decoction of (with) Ten Jujube" "Ten Chinese Dates Decoction" or "Ten Jujube Decoction". Sixth, if they are naming after effects, like" 上清丸" can be translated into "Bolus for Clearing away Heat of the Upper Heart of the Body", "Pill for Clearing away Heat from the Upper Part of the Body ". Seventh, they are made up of the principal herbs and effects, like " 止咳枇 杷糖浆 " can be translated into "Cough Syrup of Loquat Leaf", "Syrup of Loquat Leaf for Arresting Cough" and "Syrup with Loquat leaf for Arresting Cough". Eighth, using principal herbs and the number of the rests' herbs, like " 当归六黄汤 " is translated into "Chinese Angelica Decoction with Six Yellow Ingredients" or "Decoction of Chinese Angelica with Six Yellow Ingredients". Ninth, naming after color, like " 桃红散 " is translated into "Pink Powder".

\subsection{Free Translation of Prescription Names}

Free translation emphasizes the expressiveness of target text. It does not advocate word by word translation. It puts the meaning first.

There is one condition in which the prescription names should be translated through free translation method. That is, they are naming in a metaphor way, such as " 舟车丸 " can be translated into "Pill for Relieving Ascites". This prescription name cannot be translated in literal translation method, because translation in such way would make confusion and misunderstanding. Therefore, it can be translated in free translation method to deliver its effects. Besides, such prescription names like " 孔圣枕中丸 " contain the Chinese cultural elements. To make it acceptable for foreign readers and respectful to source text, it can be translated into "Confucian Pill for Hypermnesia". " 越婢汤 " is translated into "Decoction for Relieving Edema". From the Chinese, we cannot easily understand the meaning of this prescription and its effects. While, in English translation version, we can learn that this prescription is to relieve the edema. In this way, the English translation version sends the meaning to readers and presents the pharmacist's meaning.

\subsection{Transliteration of Prescription Names}

Transliteration is to translate original text into Pinyin. This translation method is chosen when literal translation and free translation are not adaptable. The purpose is to avoid cultural differences, confusion or misunderstanding.

Such prescription names as " 白虎汤 ", " 青龙白虎汤 ", " 小青龙汤 " which are the most typical of containing cultural 
elements." 小青龙汤 " is translated into "Minor Decoction of Green Dragon" is not quite appropriate. Because westerners regard "dragon" as a symbol of cruelty and evil, but in the east is opposite. Therefore, if translated in a common way regardless the cultural elements, the translation would make mistakes and confusing.

Thus, it is easily found that the main translation methods are literal translation, free translation and transliteration. Based on the characteristics and forms of prescription names, translation can be made through its function, components and dosage to make it easily understood. Added to loyalty, translation would be benefit for medical culture exchange and medical research in the world.

\section{Conclusions}

TCM prescription translation is important for research and exchange. However, there are no standards for the translation and some prescription names' translation now are complicated, ambiguous, and nonsense. According to Christiane Nord's "Functionality plus Loyalty", target texts require functionality and readability. It comes to the conclusion that literal translation, free translation, and transliteration can be used in prescription name's translation.

\section{References}

[1] Cui, Na., et al. "The Problems and Strategies in TCM Prescription Translation in View of Skopos Theory". Asia-Pacific Traditional Medicine. 24 (2015): 152153. Print.

[2] Li, Zhaoguo. "On Translation of TCM Prescriptions". Chinese Science \& Technology Translators Journal.6.4 (1993): 22-25. Print.

[3] Nord, Christiane. Translating as a Purposeful Activity: Functionalist Approaches Explained. Shanghai: $1^{\text {st }}$ ed. 2001. Print.

[4] Li, Zhaoguo. "Standardizing English Translation of Traditional Chinese Medical Terminology: An Analysis of Concepts, Principles, and Methods Concerned". Chinese Translators Journal. 4 (2008): 6395. Print

[5] Nord, Christiane. Text Analysis in Translation. Leiden: $2^{\text {nd }}$ ed. 2006. Print. 